\title{
REASSESSMENT OF CROSSRAIL TOTTENHAM COURT ROAD STATION EXCAVATION DESIGN USING THE OBSERVATIONAL METHOD OPTIMISTIC APPROACH A
}

\author{
Y. Chen ${ }^{1,2}$, D.P. Nicholson ${ }^{2}$ and G. Biscontin ${ }^{1}$ \\ ${ }^{1}$ Engineering Department, University of Cambridge, Cambridge, UK \\ ${ }^{2}$ Geotechnics, Ove Arup \& Partners, London, UK
}

\begin{abstract}
The new observational method framework with four design approaches was introduced in Ciria C760 (Ciria, 2017), its objective is to balance the safety and economy whilst dealing with geotechnical uncertainties in the retaining wall design and construction. The new observational method - Ipso tempore Modification Approach C was successfully applied to the Crossrail Tottenham Court Road Station, Western Ticket Hall (TCR-WTH) excavation and achieved savings. This case history has now been reassessed using the $A b$ initio Optimistic Approach A to demonstrate the maximised economic savings in construction materials. The reassessment adopted the most probable soil parameters calibrated in the back-analysis using the reviewed inclinometer data. The back-analysis and reassessment design were undertaken by the semi-finite element analysis programme FREW®. The wall thickness was successfully decreased in the reassessment so that the associated cost savings were achieved through less volume of excavation and concrete usage. In addition, construction time savings could be achievable, if the contingency plan was not required during construction. A contingency plan has been developed with extra prop levels to support the thinner wall under the characteristic design conditions. A cost comparison of the TCR-WTH excavation case history showed among three designs: the original design, OM Approach $\mathrm{C}$ design and OM Approach A design, the maximum economic savings can be achieved by OM Approach A. This reassessment is a valuable case study for the future application of the $A b$ initio design approaches.
\end{abstract}

\section{Notation}

$\begin{array}{ll}c_{\mathrm{u}} & \text { undrained shear strength: } \mathrm{kPa} \\ E_{\mathrm{u}} & \text { undrained soil stiffness: } \mathrm{MPa} \\ \gamma & \text { shear strain } \\ \delta_{\mathrm{H}, \mathrm{Max}} & \text { maximum wall lateral displacement: } \mathrm{mm} \\ \mathrm{A} 3 / \mathrm{A} 2 & \text { subdivisions of London Clay } \\ \mathrm{B} & \text { the width of the excavation } \\ \text { CEDS } & \text { Civil Engineering Design Standards } \\ \text { L } & \text { length of the excavation } \\ \text { LC } & \text { London Clay } \\ \text { LG } & \text { Lambeth Group } \\ \text { LMC } & \text { Lambeth Group subdivision - Lower Mottled } \\ & \text { Clay } \\ \text { OM } & \text { Observational Method } \\ \text { SAA } & \text { Shape Accel Array } \\ \text { SBP } & \text { self-boring pressure } \\ \text { SCL } & \text { sprayed concrete lining } \\ \text { SI } & \text { site investigation } \\ \text { SLS } & \text { service limit state } \\ \text { TBM } & \text { tunnel boring machine } \\ \text { TCR } & \text { Tottenham Court Road Station } \\ \text { UMC } & \text { Lambeth Group subdivision - Upper Mottled } \\ \text { ULS } & \text { Clay } \\ & \text { ultimate limit state }\end{array}$

\section{Introduction}

The observational method (OM) design and construction process has been codified in geotechnics for a few decades. However, despite the clear benefits in terms of economy, programme, and clear risk allocation, as stated in Ciria R185 (1999), the Ab initio application has been limited. A new holistic OM framework was introduced in Ciria guidance $\mathrm{C} 760$ (Ciria, 2017) and described in papers by Hardy et al. (2017; 2018). This framework identifies four design approaches for embedded retaining walls, based on the review of historical excavation case histories. The term $A b$ initio is used for OM design from the beginning of construction, covering Optimistic Approach A and Cautious Approach B. The term Ipso tempore is introduced for $\mathrm{OM}$ redesign after construction starts, comprising a newly defined Pro-active Approach $\mathrm{C}$ and the 'best-way-out' or Reactive Approach D.

Many historical excavation case histories applying the OM can be categorised as either Approach B, C or D. The only OM Approach A excavation case histories in the literature are the Harris Trust excavation temporary steel prop optimisation (Peck, 1969), and the sheet pile wall design protecting the power cable for the Channel Tunnel terminal at Folkestone (Young \& Ho, 1994). However, no actual savings regarding the construction materials and time were reported in these two $A b$ initio Approach A case histories. 
This paper reconsiders the application of the OM Approach C to the Tottenham Court Road Station, Western Ticket Hall (TCR-WTH) on the Crossrail railway project in London, UK, originally presented by Yeow et al. (2014). A review of the original inclinometer data revealed the rotation error of the SAA tubing (Chen, 2018), leading to a re-calibration of the most probable soil parameters. The new most probable soil parameters were then applied to the TCR-WTH excavation case to reassess the design and provide an indication of potential cost savings. The OM Approach A method proposed design to reduce the wall thickness with no further changes to the as-built TCR-WTH construction sequence. A cost comparison for construction materials and construction programme was then carried out on these alternatives.

\section{Crossrail TCR-WTH deep box excavation}

\subsection{Original design}

The TCR-WTH deep shaft is almost in a rectangular shape, measuring about $41 \mathrm{~m} \times 31 \mathrm{~m}$ in plan. The maximum excavation depth is approximately $29.5 \mathrm{~m}$. The original design adopted a $1.0 \mathrm{~m}$ thick diaphragm wall with five levels of temporary props using the bottom-up construction sequence. The layout of the TCR site and the section A-A' used for the TCR-WTH excavation back-analysis and reassessment are shown in Figure 1.

Figure 1 TCR-WTH layout plan and section A-A' (Chen et al. 2018)

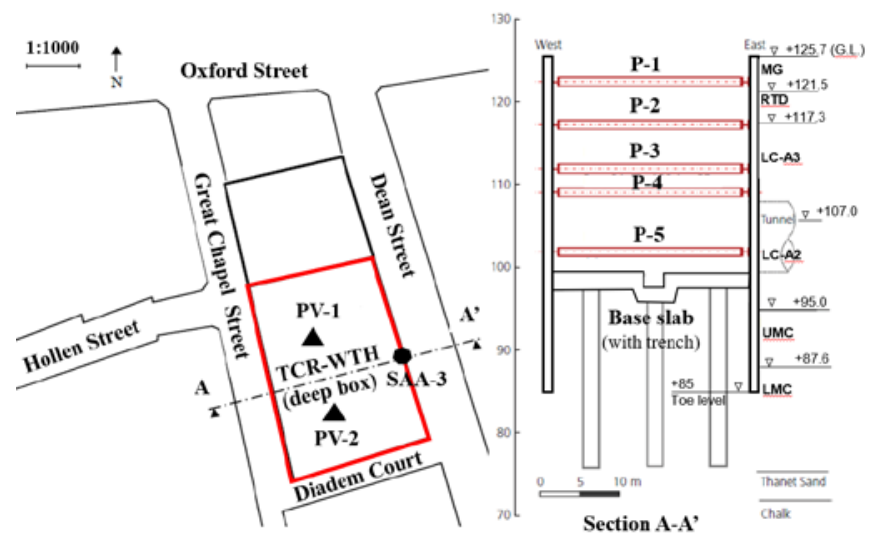

In accordance with Eurocode-based design documents, the Crossrail Civil Engineering Design Standards (CEDS) was developed and applied in the Crossrail project. The FREW model with the characteristic geotechnical parameters was used for the original design of the TCR-WTH excavation (Yeow et al., 2014).

Based on the CEDS and Ciria C580 (Ciria, 2003), the original design had adopted the mixed earth pressure approach for the short-term excavation analysis. This design assumption was for a slow top-down construction sequence with a total construction period over 12 months. Hence, the recovery of water pressure outside of the excavation box was possible.
The ground conditions observed at the TCR-WTH site were demonstrated in Figure 2: with superficial deposits (Made Ground \& Terrace Gravel) overlying London Clay and Lambeth Group. The under-drained pore-water pressure profile, the characteristic line was developed for the original design from a long-term piezometer monitoring between 1992 and 2012, as shown in Figure 2 (Yeow et al., 2014).

Figure 2 TCR-WTH porewater pressure design profiles (Yeow et al., 2014)

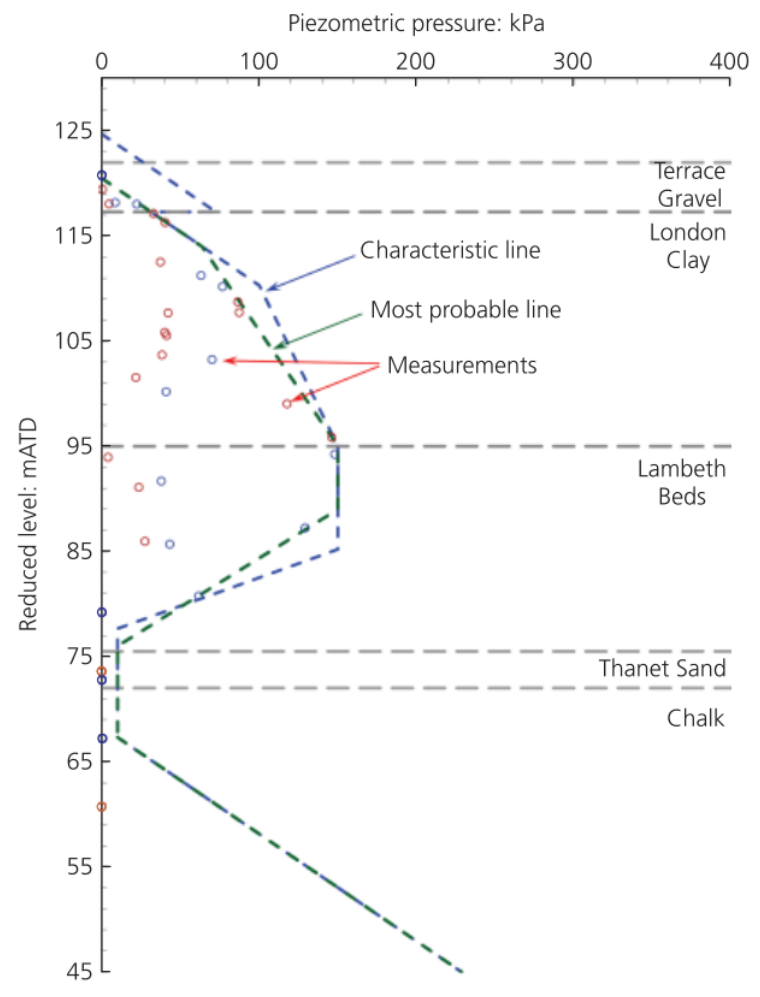

\subsection{As-built OM Approach C modified design}

A value engineering study carried out before the construction work started identifying the OM opportunity for the TCRWTH excavation. This led to increased instrumentation monitoring of the TCR-WTH, for instance, 11 numbers of the Shape Accel Array (SAA) inclinometers installed in the diaphragm wall panels. The maximum wall deflection profile during the excavation was recorded by SAA-3, its' location as shown in Figure 1.

Table 1 summarises the construction sequences in the original design and OM Approach C design. The construction followed the planned sequence as proposed in the original design. At the end of stage 3, the predicted maximum wall deflection was almost twice the measured raw data at SAA-3 location (Figure 3 ). This provided evidence to support the implementation of the OM Approach C.

The back-analysis of the retaining wall deflection profile was carried out regarding the as-built construction sequence, so that the most probable Mohr-Coulomb soil parameters for London Clay could be calibrated for the OM Approach $\mathrm{C}$ modified 
design. The result of the wall deflection profile at stage 3 was fitted to the raw SAA-3 readings, as shown in Figure 3.

Table 1 Summary of TCR-WTH excavation sequence

\begin{tabular}{llc}
\hline Stage & Description & $\begin{array}{l}\text { Formation level } \\
\text { (m ATD) }\end{array}$ \\
\hline 1 & Excavate 1 & +121.6 \\
2 & Install P-1 \& Excavate 2 & +116.4 \\
3 & Install P-2 \& Excavate 3 & +111.1 \\
4 & Install P-3 \& Excavate 4 & +108.1 \\
5 & Install P-4 \& Excavate 5 & +101.0 \\
6 & Install P-5 ${ }^{a}$ \& Excavate 6 & +96.8 \\
7 & Cast base-slab & +98.9 \\
\hline
\end{tabular}

aP-5 was planned in the original design but omitted in the as-built

construction following Approach C modified design. (Chen et al. 2018)

Figure 3 Wall deflection profiles: predictions versus SAA-3 raw data (Chen et al. 2015)

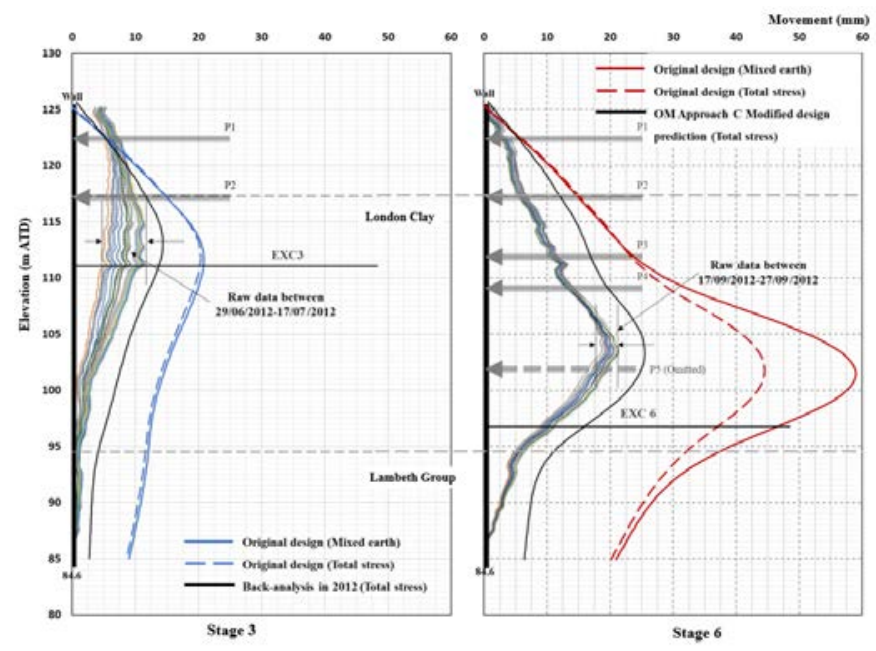

Because the change from the top-down to the bottom-up construction sequence in the original design has minimized the excavation duration ( $<12$ months period), facilitated the earliest possible construction of the base slab and preparatory sprayed concrete lining tunnelling (SCL) works in advance of the arrival of the twin tunnel boring machines (TBMs) (Yeow et al, 2014). This change also enabled the total earth pressure approach (undrained at both active and passive sides) for the short-term excavation analysis. Therefore, the back-analysis reviewed the mixed earth pressure and total earth pressure approached, showing the negligible impact on the wall deflection back-analysis at the shallower excavation depth (e.g. stage 3), but the significant impact at the deeper excavation depth (e.g. stage 6).

The pore-water pressure profile was adjusted in the backanalysis of the OM Approach $\mathrm{C}$ modified design, as shown as the most probable line in Figure 2 (Yeow et al., 2014). It was envisaged that total stress design conditions would be more appropriate for the back-analysis, based on the fast excavation process. In addition, two extensometers installed next to the piezometers (PV1 \& PV2 in Figure 1) inside the excavation box did not show significant swelling movements during excavation (Chen, 2018).

The design conditions adopted for the original design and the back-analysis of the OM Approach $\mathrm{C}$ modified design were summarised in Table 2.

Table 2 Comparison of design conditions

\begin{tabular}{lcc}
\hline $\begin{array}{l}\text { Design / } \\
\text { assumptions }\end{array}$ & $\begin{array}{c}\text { Original design } \\
(2011)\end{array}$ & $\begin{array}{c}\text { Back-analysis } \\
(2012)\end{array}$ \\
\hline $\begin{array}{l}\text { Short-term } \\
\text { excavation }\end{array}$ & Mixed earth pressure & Total stress \\
Over-dig a $^{\text {O }}$ & 0.5 m or $10 \% h$ & na \\
Softening $^{\text {a }}$ & $80 \%$ at passive side & na \\
\hline
\end{tabular}

aThe least over excavation depth between $0.5 \mathrm{~m}$ and $10 \%$ of the shortest vertical distance from the excavated level to the lowest prop $(h)$ and reduction of soil strength at the passive side are applied for the short-term ULS (ultimate limit state) analysis.

Besides the updates on the design conditions, the back-analysis calibrated the most probable geotechnical parameters associated with the undrained Mohr-Coulomb parameters for the total stress analysis. They were compared with the characteristic parameters applied in the original design, as presented in Table 3.

Table 3 Summary of geotechnical undrained parameters

\begin{tabular}{lccc}
\hline Parameter/ & Top & Characteristic & Most probable \\
stratum & (m ATD) & $(2011)$ & $(2012)$
\end{tabular}

\begin{tabular}{lccc}
\hline $\boldsymbol{c}_{\mathbf{u}}(\mathbf{k P a})$ & & & \\
LC-A3 & +117.3 & $80+8 \mathrm{z}^{\mathrm{b}}$ & $100+8 \mathrm{z}$ \\
LC-A2 & +106.2 & 250 & $182.4+14 \mathrm{z}$ \\
LG & +95.0 & 250 & 350
\end{tabular}

\begin{tabular}{lccc}
\hline $\boldsymbol{E}_{\mathbf{u}}(\mathbf{M P a})$ & & & \\
$\mathrm{LC}-\mathrm{A} 3$ & +117.3 & $76+3.9 \mathrm{z}$ & $1000 c_{\mathrm{u}}$ \\
$\mathrm{LC}-\mathrm{A} 2$ & +106.2 & $109+7.0 \mathrm{z}$ & $1000 c_{\mathrm{u}}$ \\
$\mathrm{LG}$ & +95.0 & ${ }^{\mathrm{c}} 148+3.8 \mathrm{z}$ & $2000 c_{\mathrm{u}}$
\end{tabular}

${ }^{\mathrm{a} I n}$ the As-built OM Approach C design, $\mathrm{c}_{\mathrm{u}}$ for London Clay was recommended for the subdivisions of $\mathrm{A} 3$ and $\mathrm{A} 2 .{ }^{\mathrm{b}} \mathrm{z}=0$ at top of the stratum. ${ }^{\mathrm{c}}$ The characteristic undrained stiffness was based on the laboratory triaxial testing results at $0.1 \%$ strain level.

The calibrated most probable geotechnical design parameters and the most probable design conditions have enabled the OM Approach $\mathrm{C}$ modified design allowing the lowest level of temporary props (P5) to be omitted. However, a design would need to cover all possible conditions. Therefore, the mixed earth design condition was applied to the backup contingency plan in accordance with the CEDS and Ciria C580 (Ciria, 2003). This plan involved final excavation using berms and bays as well as a blinding strut at formation level instead of the $5^{\text {th }}$ level of props. 
The as-built construction did not implement the contingency plan. The successfully modified design by the OM Approach $\mathrm{C}$ achieved costs saving of $£ 715,000$, including about four weeks on the program (Yeow et al. 2014).

\section{Reassessment by OM Approach A}

\subsection{Re-calibration of most probable geotechnical parameters}

The review of the SAA raw data raised a concern on the data accuracy. For example, at stage 3 up to $1.5 \mathrm{~mm}$ lateral deflection was noted over the bottom $10 \mathrm{~m}$ of the wall, even though the formation level was about $25 \mathrm{~m}$ above the wall toe (Figure 3). Discussions with the inclinometer supplier highlighted the need to correct for the rotation of the SAA tubing occurring during installation (Chen, 2018). The corrected SAA-3 data are presented in Figure 5, showing a significant reduction of the maximum wall lateral movements compared to the raw data shown in Figure 3. This necessitated the re-calibration of the most probable design parameters.

The second back-analysis was based on the FREW model used in the OM Approach $\mathrm{C}$ modified design and extended to include the as-built construction details to the end of the excavation (stage 6). The difference between the measured and back-calculated wall deflections was limited to less than $5 \mathrm{~mm}$ to allow for errors, such as the unavoidable instrument (SAA) errors and the FREW modelling errors.

In the second back-analysis, a supervised linear statistical regression line method was proposed to derive the input parameters from the SI testing data, such as the undrained shear strength $\left(c_{\mathrm{u}}\right)$. So that the subjective interpretation of design values could be minimized. It was found useful to fix the value at the top of the stratum where the scatter was generally less. The undrained shear strength design profiles are presented against the testing data for London Clay and Lambeth Group in Figure 4. The calibrated and re-calibrated undrained soil stiffness $\left(E_{\mathrm{u}}\right)$ design profiles are compared with the triaxial testing data at three strain levels as presented in Figure 4.

The most probable Mohr-Coulomb soil parameters were recalibrated in the second back-analysis. The predicted wall deflections at stage 3 and stage 6 by the re-calibrated design parameters are compared against the OM Approach $\mathrm{C}$ modified design results and the anti-rotational corrected inclinometer data in Figure 5.

Figure 4 OM Approach A design: (a) Revised undrained shear strength design profile; (b) Revised undrained soil stiffness design profile.

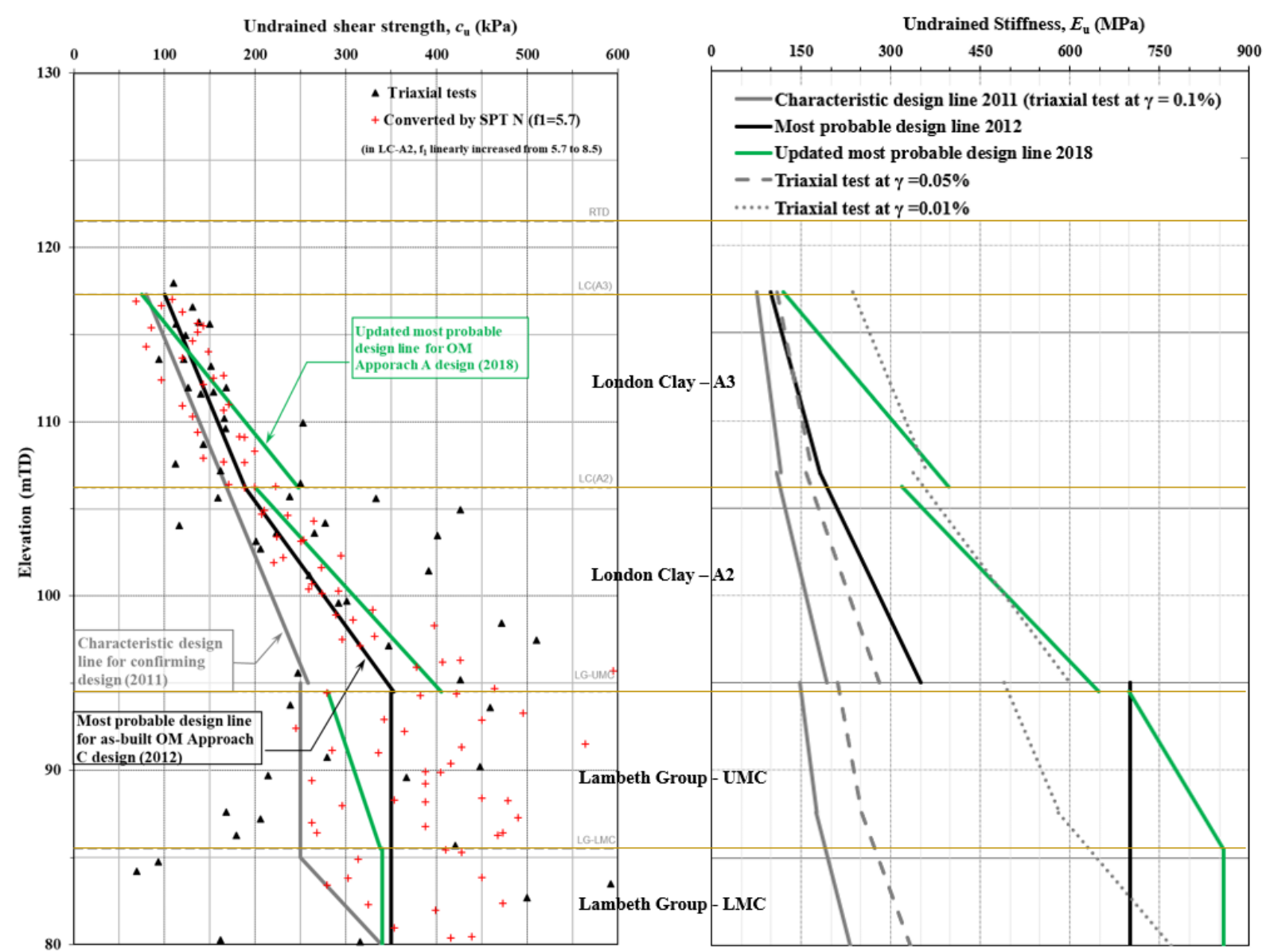

(a) 
Figure 5 Wall deflection profiles: predictions versus SAA-3 corrected data

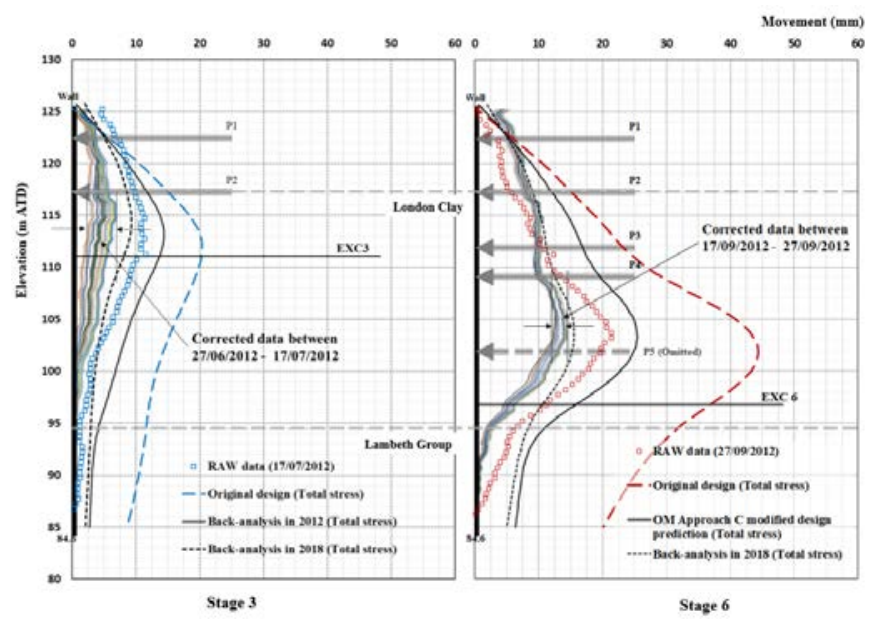

\subsection{OM Approach A design}

The OM Approach A design of the TCR-WTH excavation was undertaken with the re-calibrated most probable soil parameters, in accordance with BSI (2004a; 2004b) and referenced to Ciria C760 (Ciria, 2017). This alternative design offers a chance to evaluate further refinements and savings which could be made when major geotechnical uncertainties soil parameters were removed. In the design, the as-built construction details of the TCR-WTH excavation have been maintained regarding type and depth of the retaining wall, temporary propping details, excavation sequence, and other site activities (e.g. ground compensation grouting for the SCL work).

The major change was to decrease the diaphragm wall thickness from the original $1.0 \mathrm{~m}$ to $0.8 \mathrm{~m}$. The OM Approach A has used the same four level of temporary props per as-built OM Approach C modified design in 2012.

The most probable design conditions were applied for the $\mathrm{OM}$ Approach A design, as verified in the back-analysis in 2012 and summarised in Table 2: the total stress analysis for shortterm excavation without over-dig or soil strength reduction in the ULS designs.

Meanwhile, the contingency plan proposed two additional levels of props $\left(5^{\text {th }}\right.$ and $\left.6^{\text {th }}\right)$ for the cautious design conditions as assumed in the original design and summarised in Table 2 . The cautious design conditions are associated with uncertainty in soil permeability, drainage paths and construction duration. The OM Approach A and contingency plan excavation sequence are summarised in Table 4.

Under the SLS (service limit state) analysis, the wall performance (e.g. predicted wall deflections) was reviewed. The predicted wall deflection profiles for the $0.8 \mathrm{~m}$ thick wall at the final excavation stage were compared with the red trigger profile developed for the $1.0 \mathrm{~m}$ thick wall in the as-built $\mathrm{OM}$ Approach $\mathrm{C}$ modified design (Figure 6). Both the OM Approach A design and the contingency plan with a thinner wall show the improved performance - the smaller deflections than the red trigger profile controlling the as-built construction. Hence, the OM Approach A design with the contingency plan is considered as acceptable.

Table 4 Summary of the OM Approach A excavation sequence of the TCR-WTH deep box excavation

\begin{tabular}{lll}
\hline Stage & Description & $\begin{array}{l}\text { Formation level } \\
\text { (m ATD) }\end{array}$ \\
\hline 1 & Excavate 1 & +121.6 \\
2 & Install P-1 \& excavate 2 & +116.4 \\
3 & Install P-2 \& excavate 3 & +111.1 \\
4 & Install P-3 \& excavate 4 & +108.1 \\
5 & Install P-4 \& excavate 5 & +101.0 \\
$5^{a}$ & Install P-4 \& excavate 5 & +104.1 \\
6 & Excavate 6 & +96.8 \\
$6^{a}$ & Install P-5 \& excavate 6 & +101.0 \\
7 & Cast base-slab & +98.9 \\
$7^{a}$ & Install P-6 \& excavate 7 & +96.8 \\
8 & Cast base-slab & +98.9 \\
\hline
\end{tabular}
a If the construction followed the contingency plan.

The structural design for the reinforcement design to the $0.8 \mathrm{~m}$ diaphragm wall, was carried out in accordance with BSI (2010). Outputs from the ULS (ultimate limit state) analyse, the maximum values of the combination 1 and combination 2 were used to develop the reinforcement design. The OM Approach A design with the contingency plan bending moment (BM) envelope for the $0.8 \mathrm{~m}$ wall is presented in Figure 6.

In summary, it is based on the SLS performance check and the ULS structural capacity check, the OM Approach A design for the TCR-WTH deep box excavation is valid.

\subsection{Comparison of most probable undrained parameters}

The most probable soil parameters were applied in the as-built OM Approach C modified design and the OM Approach A optimistic design. The difference between the above two sets of parameters is due to the rotational error of SAA tubing in the inclinometer data. A comparison of these two sets of most probable geotechnical undrained parameters is presented in Table 5 .

The supervised linear statistical regression line method in the second back-analysis has derived the updated undrained shear strength $\left(c_{\mathrm{u}}\right)$ design line with the steeper gradients for each stratum, as demonstrated in Figure 4.

The updated most probable undrained soil stiffness $\left(E_{\mathrm{u}}\right)$ design values for London Clay are closer to the triaxial testing result at small strain level $(0.01 \%)$, see Figure 4 . Whilst the most probable $E_{\mathrm{u}}$ design values for London Clay recommended in 2012 are matching the triaxial testing results at the strain level of $0.05 \%$.

Regarding the Lambeth Group, the updated most probable undrained shear strength $\left(c_{\mathrm{u}}\right)$ design line was compromised from the highly scattered testing results, see Figure 4. 
Figure 6 Output of OM Approach A design: (a) Wall deflection profiles at final excavation stage 6; (b) Bending moment envelope.

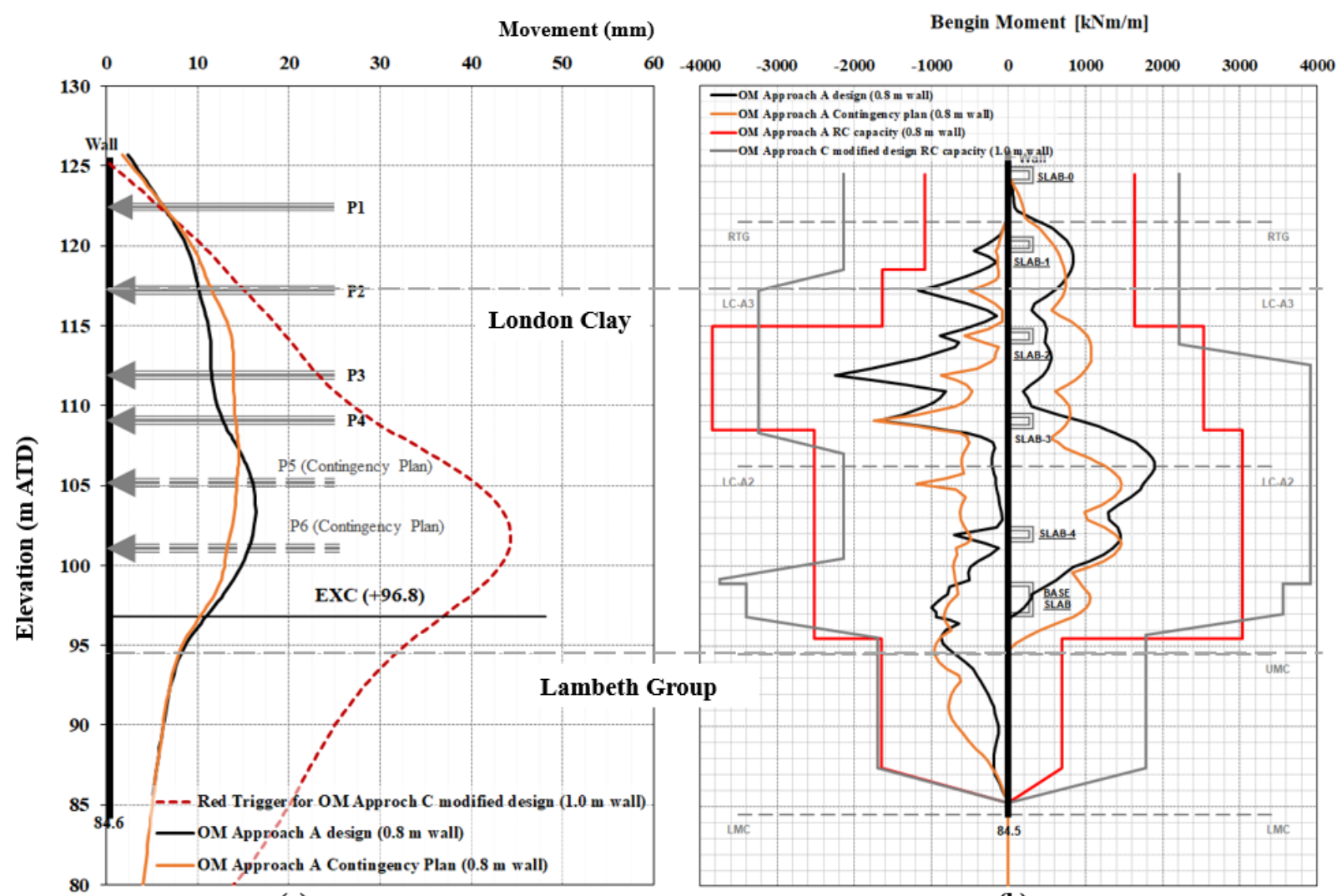

(a)

(b)

Note: the predicted wall deflection envelops are for the short-term excavation under the total stress design conditions; the envelope of $\mathrm{BM}$ (bending moment) include the short-term and long-term conditions.

Table 5 Comparison of most probable geotechnical undrained parameters

\begin{tabular}{lccc}
\hline $\begin{array}{l}\text { Item/ } \\
\text { stratum }\end{array}$ & $\begin{array}{l}\text { Top } \\
(\mathrm{m} \text { ATD) }\end{array}$ & $\begin{array}{c}\text { Most probable } \\
(2012)\end{array}$ & $\begin{array}{c}\text { Updated Most } \\
\text { probable }(2018)\end{array}$ \\
\hline $\boldsymbol{c}_{\mathbf{u}} \mathbf{( k P a )}$ & +117.3 & $100+8 \mathrm{z}$ & $75+15.6 \mathrm{z}$ \\
$\mathrm{LC}-\mathrm{A} 3$ & & $182.4+14 \mathrm{z}$ & $200+17.5 \mathrm{z}$ \\
$\mathrm{LC}-\mathrm{A} 2$ & +106.2 & 350 & $280+6.4 \mathrm{z}$ \\
$\mathrm{UMC}$ & +94.5 & & 350 \\
$\mathrm{LMC}$ & +85.5 & & \\
\hline $\boldsymbol{E}_{\mathbf{u}}(\mathbf{M P a})$ & & & $1750 c_{\mathrm{u}}$ \\
$\mathrm{LC}^{\mathrm{a}} \mathrm{A} 3$ & +117.3 & $1000 c_{\mathrm{u}}$ & $2000 c_{\mathrm{u}}$ \\
$\mathrm{LC}^{\mathrm{a}} \mathrm{A} 2$ & +106.2 & $1000 c_{\mathrm{u}}$ & $4000 c_{\mathrm{u}}$ \\
$\mathrm{UMG}^{\mathrm{a}}$ & +94.5 & $2000 c_{\mathrm{u}}$ & $4000 c_{\mathrm{u}}$ \\
$\mathrm{LMG}^{\mathrm{a}}$ & +85.5 & & \\
\hline
\end{tabular}

${ }^{\mathrm{a} I n}$ OM Approach A design, $\mathrm{c}_{\mathrm{u}}$ for Lambeth Group was recommended for the subdivisions of LMC and UMC.

However, the very stiff most probable undrained soil stiffness $\left(E_{\mathrm{u}}\right)$ values for the Lambeth Group are higher than the corresponding triaxial testing results at the small strain level of $0.01 \%$, see Figure 4 . This only indicates that very small strains developed in the Lambeth Group soils during the TCR-WTH deep box excavation. If the excavation occurred in this stratum, larger strains could be developed, hence, the most probable undrained soil stiffness $\left(E_{\mathrm{u}}\right)$ values may be reduced.

It should be noted that these most probable stiffness parameters have been calibrated and re-calibrated using the FREW model (2D semi-finite element model) with the Mohr-Coulomb elastic plastic soil model, the actual TCR WTH deep box excavation with 3D geometry effects would reduce the most probable soil stiffness.

\subsection{Comparison of costs}

The cost comparison for the original design, the OM Approach $\mathrm{C}$ modified design and the $\mathrm{OM}$ Approach A design is summarised in Table 6. The cost estimation for the OM Approach A design is based on the savings achieved in the asbuilt OM Approach C modified design (Yeow et al., 2014). The comparison is divided into the construction material cost: concrete and steels, and the construction time cost.

From the simplified comparison, it becomes clear that the diaphragm wall volume (excavation and concrete) accounts for the major part of the construction material cost in the TCRWTH excavation case history. In the as-built OM Approach C modified design, concrete has been poured to form the $1.0 \mathrm{~m}$ thick wall per the original design. Hence, there were only $3 \%$ 
savings achieved in construction material by omitting the $5^{\text {th }}$ level of props.

The OM Approach A design will also have one level of props omitted, but the thinner $0.8 \mathrm{~m}$ diaphragm wall will reduce $20 \%$ in the wall excavation and the poured concrete volume. The total saving in construction material by the OM Approach Optimistic A design by $0.8 \mathrm{~m}$ diaphragm wall could be up to $32 \%$ compared with the original design by the $1.0 \mathrm{~m}$ diaphragm wall. Meanwhile, the reduced excavation and less concrete will make the OM Approach A design a more sustainable option.

The construction time is also a crucial financial factor for the Crossrail TCR-WTH deep box excavation case history. This is reflected in the as-built OM Approach $\mathrm{C}$ modified design, in which the major savings (11\%) has been achieved by the shortened construction period by 4 weeks.

Table 6 Comparison of excavation costs

\begin{tabular}{|c|c|c|c|}
\hline $\begin{array}{l}\text { Design/ } \\
\text { Items }\end{array}$ & $\begin{array}{l}\text { Original } \\
\text { design } \\
(2011)\end{array}$ & $\begin{array}{c}\text { Approach } \\
\text { C design } \\
(2012)\end{array}$ & $\begin{array}{c}\text { Approach A } \\
\text { design } \\
(2018)\end{array}$ \\
\hline Retaining & $1.0 \mathrm{~m}$ & $1.0 \mathrm{~m}$ & $0.8 \mathrm{~m}$ \\
\hline wall & ${ }^{\mathrm{a} D}$ Dall & Dwall & Dwall \\
\hline Cost (£:M) & 4.32 & 4.32 & 2.84 \\
\hline $\begin{array}{l}\text { Temporary } \\
\text { prop }\end{array}$ & 5 levels & 4 levels & $\begin{array}{c}4 \text { levels } \\
6 \text { levels } \\
\left({ }^{\mathrm{b}} \mathrm{CP}\right)\end{array}$ \\
\hline Cost (£:M) & 0.7 & 0.56 & $\begin{array}{c}0.56 \\
0.84(\mathrm{CP})\end{array}$ \\
\hline $\begin{array}{l}\text { Total } \\
\text { material cost } \\
(£: M)\end{array}$ & $\sim 5.02$ & $\sim 4.88$ & $\begin{array}{c}\sim 3.40 \\
\sim 3.68(\mathrm{CP})\end{array}$ \\
\hline $\begin{array}{l}\text { Material } \\
\text { saving (\%) }\end{array}$ & na & $\sim 3 \%$ & $\begin{array}{c}\sim 32 \% \\
\sim 26 \%(\mathrm{CP})\end{array}$ \\
\hline $\begin{array}{l}\text { Programme } \\
(\text { week) })^{c}\end{array}$ & $\sim 28$ & 24 & $\begin{array}{c}\sim 22 \\
\sim 30(\mathrm{CP})\end{array}$ \\
\hline $\begin{array}{l}\text { Saved time } \\
\text { (week) }\end{array}$ & na & +4 & $\begin{array}{c}+6 \\
-2(\mathrm{CP})\end{array}$ \\
\hline $\begin{array}{l}\text { Time cost } \\
(£: M)^{d}\end{array}$ & na & $\sim 0.58$ & $\begin{array}{c}\sim 0.87 \\
\simeq-0.29(\mathrm{CP}) \\
\end{array}$ \\
\hline $\begin{array}{l}\text { Time saving } \\
(\%)\end{array}$ & na & $\sim 11 \%$ & $\begin{array}{c}\sim 17 \% \\
\sim-6 \%(\mathrm{CP}) \\
\end{array}$ \\
\hline $\begin{array}{l}\text { Total saving } \\
(\%)\end{array}$ & na & $\sim 14 \%$ & $\begin{array}{c}\sim 49 \% \\
\sim 20 \%(\mathrm{CP})\end{array}$ \\
\hline
\end{tabular}

${ }^{\mathrm{a} D w a l l}=$ diaphragm wall. ${ }^{\mathrm{b}} \mathrm{CP}=$ contingency plan. ${ }^{\mathrm{c} P r o g r a m m e}$ refers to the duration up to the end of the final excavation: the original design programme was planned, the OM Approach $\mathrm{C}$ modified design programme was confirmed by the as-built record, and the OM approach A design with Contingency plan programmes were estimated based on the as-built record. ${ }^{\mathrm{d}}$ Cost of time was estimated based on the achieved saving in the as-built OM approach $\mathrm{C}$ modified design reported by Yeow et al (2014).

For the TCR-WTH deep box excavation case, the total cost saving of the OM Approach A reassessment, compared to the original design, is between $20 \%$ and $49 \%$. The lower saving percentage is taking account of the possibility when the contingency plan may be required and cost time to install extra props.

Figure 7 displays the value assessment results for the TCRWTH deep box excavation re-assessment. The diagram indicates under the $\mathrm{OM}$ Approach $\mathrm{C}$ modified design, the achievable cost saving is limited. However, the $A b$ initio Approach A design can deliver more cost-effective designs regarding the construction material cost. Although this Approach A design is accompanied by the contingency plan which allows for the risk associated prolonged excavation duration.

Figure 7 Cost comparison for TCR-WTH deep box excavation case history

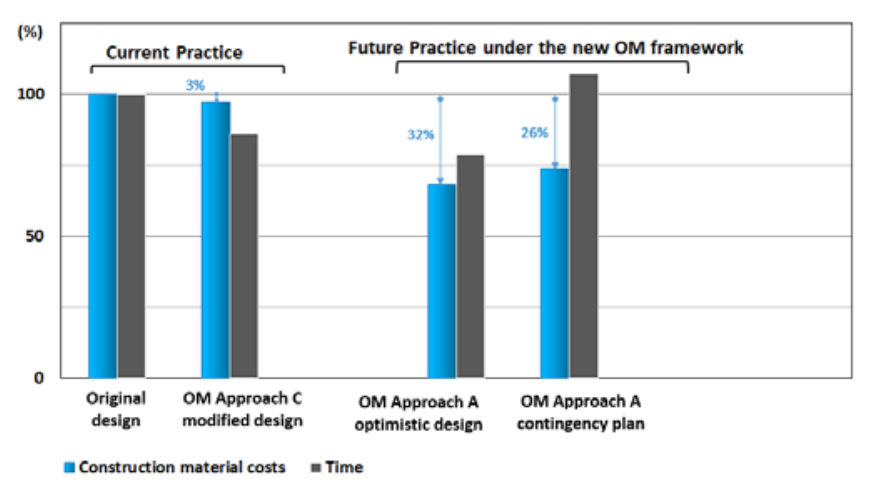

\section{Conclusions}

The Crossrail TCR-WTH deep box excavation original design in 2011 and the OM Approach C modified design in 2012 were reviewed. A reassessment by the $A b$ initio Optimistic Approach A was also carried out using the same FREW model used for original design and back-analysis. Therefore, all the modelling assumptions are incorporated.

In the as-built OM Approach $\mathrm{C}$ modified design, the most probable Mohr-Coulomb soil parameters for London Clay were calibrated using the inclinometer raw data. The review of the inclinometer data has identified the rotational error of SAA tubing during installation. The anti-rotational correction on the inclinometer raw data led to the reduced wall deflections and the re-calibrated most probable Mohr-Coulomb soil parameters for London Clay.

The reassessment of the TCR-WTH deep box excavation design was carried out using the re-calibrated most probable soil parameters and the most probable design conditions by the OM Approach A. A back-up contingency plan was developed for the cautious design conditions.

The cost comparison of the original design, the OM Approach $\mathrm{C}$ modified design and the OM Approach A design shows the OM Ab initio optimistic Approach A method can maximise the cost saving in construction materials, and potentially minimising the duration of the excavation work. 
In future, OM Approach A optimistic design for excavations in London Clay can benefit from this TCR-WTH deep box excavation case history knowledge, and safety assurance provided by the back-up contingency plan.

It is noted the FREW model uses a series of modelling assumptions. They must be maintained on other excavations if the FREW model is adopted for design and back-analysis. These have been studied by comparing the FREW model with the Plaxis 2D and LS-Dyna 3D for the TCR-WTH deep box excavation case history (Chen, 2018).

The successful reassessment of the OM Approach A relies on a few factors: the reliable inclinometer data, the calibrated most probable design parameters in the back-analysis, and the good OM case history of the TCR-WTH deep box excavation.

\subsection{Most probable geotechnical design parameters}

The most probable geotechnical design parameters are calibrated through the back-analysis using the field monitoring data. The following recommendations are listed for the better back-analysis, therefore, the better calibrated most probable design parameters.

1) Care is required to interpret reliable inclinometer data. The monitoring data review is recommended to include in the instrument and monitoring specification, particularly for the construction adopted the OM design.

2) In the back-analysis, the predictions are subjected to the calculation or modelling deployed to carry out analysis. Hence, it is recommended to use the same modelling adopted in the original design for the backanalysis. Also, the calibrated most probable design parameters will only be valid for the same type of modelling in the future OM design.

3) The back analyses and the reassessment for the TCRWTH deep box excavation case history have been carried out assuming the undrained condition of London Clay (total stress analysis), as the most probable design condition during the excavation work. This total stress design condition can be considered as a characteristic design case for rapid construction.

In the second TCR-WTH deep box excavation back-analysis, the most probable Mohr-Coulomb soil parameters for the London Clay subdivisions A3 and A2 were re-calibrated. Given that the uniformity of the over-consolidated London Clay across the central London area, it enables the application of these most probable parameters to future excavation in London Clay by the OM approaches.

The most probable undrained shear strength $\left(c_{\mathrm{u}}\right)$ design profile is recommended to be derived from the testing data by a more robust method - the supervised statistical linear regression method so that the manual influence can be minimized.
The most probable undrained soil stiffness $\left(E_{\mathrm{u}}\right)$ design profile for London Clay is found closer to the laboratory triaxial testing result at the small strain level of $0.01 \%$. Large scatter of the small strain triaxial tests were observed making it difficult to rely on this data alone. There were few laboratories small strain triaxial tests from the Lambeth Group. The further study on this soil stiffness is required through both the in-situ and laboratory tests. The back-analysed most probable $E_{\mathrm{u}}$ design profile for Lambeth Group was associated with very small strain and may not be appropriate for larger wall deflections.

\subsection{Maximised savings}

The cost comparison of the TCR-WTH deep box excavation case history demonstrates the new OM framework - $A b$ initio Approach A is a cost-effective design method, which achieved the maximised saving in construction materials, and potentially the shortest the duration of the excavation work if the back-up contingency plan is not required.

\section{Acknowledgement}

The authors would like to thank their colleagues at the University of Cambridge and Ove Arup \& Partners Geotechnics London Office for their contribution during the case history study and compilation of this paper. The authors would like to thank the Crossrail Ltd for the help on case history and permission to publish the data presented. The authors extend their gratitude to Dr Andrew Ridley (Geo Observations Ltd) and Mr Alistair Ringer (Kier Professional Services Ltd), who provided technical assistance and support during the preparation of this paper.

\section{Reference}

BSI (2004a) BS EN 1997-1: Eurocode 7: Geotechnical design - Part 1: General rules. BSI (British Standard Institution), London, UK.

BSI (2004b) UK National Annex to Eurocode 7: Geotechnical design Part 1: General rules. BSI (British Standard Institution), London, UK.

BSI (2010) BS EN 1990:2002+A1: Eurocode - Basis of structural design. BSI (British Standard Institution), London, UK.

Bologna P (2017) Benchmarking empirical methods of prediction of ground movement for deep excavation. MSc Thesis, University of Cambridge, Cambridge, UK.

Chen Y (2018) Application of new observational method on deep excavation retaining wall design in London. $\mathrm{PhD}$ Thesis, University of Cambridge, Cambridge, UK.

Chen Y, Nicholson DP, Ingram P, Hardy S, Liew HL, Farooq I, and Biscontin G (2015) Application of the observational method on Crossrail projects. Proceeding of Crossrail: A specialist Foundation Construction Lessons Learnt Conference, London. The UK. London. ICE (Institution of Civil Engineering) publishing, pp. 63-72. 
Ciria (1999) R185: The Observational Method in Ground Engineering - Principle and Applications. Ciria (Construction Industry Research and Information Association), London, UK. Ciria (2003) C580: Embedded retaining walls-guidance for economic design. Ciria (Construction Industry Research and Information Association), London, UK.

Ciria (2017) C760: Guidance on embedded retaining wall design. Ciria (Construction Industry Research and Information Association), London, UK.

Hardy S, Nicholson DP, Ingram P, Gaba A, Chen Y and Biscontin G (2017) New observational method framework for embedded walls. Proceedings of $19^{\text {th }}$ International Conference on Soil Mechanics and Geotechnical Engineering, Seoul. Korea.

Hardy S, Nicholson DP, Ingram P, Gaba A, Chen Y and Biscontin G (2018) New observational method framework for embedded walls. Geotechnical Research, 5(3), pp. 122-129.

Peck RB (1969) Advantages and Limitations of the Observational Method in Applied Soil Mechanics. Ninth Rankine Lecture, Géotechnique, Vol. 19 (2), pp. 171-187

White F, Ingram P, Nicholson DP, Stroud M and Betru M (2019) An update of the SPT $-c_{u}$ relationship proposed by M. Stroud in 1974. Proceedings of the XVII European Conference of Soil Mechanics Geotechnical Engineering, Reykjavik. Iceland.

Yeow HC, Nicholson DP, Man CL, Ringer A, Glass P and Black M (2014) Application of observational method at Crossrail Tottenham Court Road station, UK. Geotechnical Engineering, 167(GE2), pp.182-193.

Young DK and Ho EWL (1994) The observational approach to design of a sheet-piled retaining wall. Géotechnique, 44(4), 637-654. 